\title{
Diabetics and Oral Health: A Case-Control Study
}

\author{
Dr. Mohammad Nazmul Kabir ${ }^{*}$, Dr. Md. Monoarul Islam² ${ }^{2}$ Dr. Md. Shahrin Tarafder ${ }^{3}$
}

\section{AFFILIATION:}

1. Dr. Mohammad Nazmul Kabir

BDS, DDS, BCS (Health)

Assistant Professor, Dentistry, Cox's Bazar Medical College, Cox's Bazar.

2. Dr. Md. Monoarul Islam BDS, DDS, MCPS, BCS (Health)

Assistant Professor, Dentistry

Rangpur Medical College, Rangpur.

3. Dr. Md. Shahrin Tarafder

BDS, DDS (BSMMU),

Assistant Professor, Dentistry, OSD DGHS,

Attached Kurmitola General Hospital,

Dhaka Cantonment, Dhaka.

Article info.

Received: 11 June 2021

Accepted: 04 August 2021

Volume: Vol-11, Issue-2, October 2021

DOI: https://doi.org/10.3329/updcj.v11i2.56093

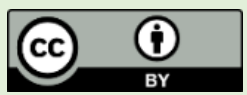

(C) Authors retain copyright and grant the journal right of first publication with the work simultaneously licensed under Creative Commons Attribution License CC - BY 4.0 that allows others to share the work with an acknowledgment of the work's authorship and initial publication in this journal.

https://creativecommons.org/licenses/by/4.0/

Publisher: Update Dental College, Dhaka, Bangladesh

Web: www.updatedentalcollege.edu.bd

E-mail: updcj@hotmail.com

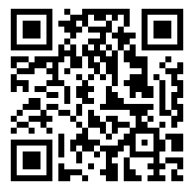

\author{
Scan QR code to see the latest issue \\ * Corresponding Author \\ Dr. Mohammad Nazmul Kabir \\ BDS, DDS, BCS (Health), \\ Assistant Professor, Dentistry, \\ Cox's Bazar Medical College, Cox's Bazar. \\ Email: drmanazmulkabir@gmail.com
}

Cell: 01712776618

\begin{abstract}
:
Background: Diabetes is a predominant health problem today and characterized by abnormally high blood sugar. According to World Health Organization (WHO) this clinical condition is increasing worldwide due to urbanization and physical inactivity uncontrolled diabetes develop ulceration, infection, tooth decay and decrease oral health status. Objectives: For the assessment of oral health condition and according to treatment required among the diabetic and non-diabetic patients is dental department of Cox's Bazar Medical College Hospital, Cox's Bazar. Method: This was a case-control type of study which carried among 150 diabetics and 150 non-diabetics for 8 months period. Date was collected by direct interview of both diabetics and non-diabetics and clinical examination of oral cavity \& also lab test. Results: Prevalence of Dental caries were higher in diabetics (58.6\%) than nondiabetics (21.6\%) and also prevalence of periodontal disease more in diabetics $(93.2 \%)$ than non-diabetics $(82.6 \%)$. Conclusion: Oral health is mirror image of general health. Dental caries and periodontal disease is more in diabetics than non-diabetics complex treatment required more in diabetics than nondiabetics. So, regular dental care is necessary for diabetic patients.
\end{abstract}

KEY WORDS: Oral Health problem, periodontitis, Dental Decay, Diabetics.

\section{INTRODUCTION:}

Diabetics Mellitus is a clinical condition characterized by Hyperglycemia due to absolute or relative deficiency of insulin. ${ }^{1}$ According to WHO, about 422 million people worldwide have diabetics, most of them are low and middle income countries and 1.6 million deaths are directly due to diabetics each year WHO declares that diabetes is increasing day by day and it will be reach 700 million by $2045^{2}$.

Diabetes causes lower resistance to infection, low healing rate and which ultimately develop oral health problem such as taste disturbances, dry/burning mouth, lichen planus and also systemic problem.

The number of people with diabetics is increasing due to aging, urbanization and increase prevalence of obesity and physical inactivity. ${ }^{3}$ Now a day diabetics is major burden upon health care facilities in all countries.

MATERIALS METHODS:

This study was a case-control type of Study which carried out in the dental department of Cox's Bazar Medical college Hospital. This Study was conducted from June 2020 to January 2021. A total 150 Diabetics (Males-90, females-60) and 150 Non-diabetics (Males-78, Females-72) is the age group of 3070 Years were selected for the study who visiting the out patients department of Cox's Bazar Medical College hospital for dental problem. from June 2020 To January 2021. Data were collected by simple random sampling technique through direct interview of both diabetics and non-diabetics patients and clinical examination of oral cavity. The control group have no known disease and used no drugs. A verbal consent was taken from the study samples.

RESULTS:

The study was carried out among 150 diabetics patients and 150 non-diabetics patients of Cox's Bazar Medical College Hospital, Cox's Bazar from June 2020 to January 2021. Data 
was presented through tables and figures and they are given below:

Table I: Distribution of Study population according to sex.

\begin{tabular}{lllll} 
Gender & \multicolumn{2}{l}{ Diabetics $(\mathbf{N}=\mathbf{1 5 0})$} & \multicolumn{2}{c}{ Non-Diabetics $(\mathbf{N}=\mathbf{1 5 0})$} \\
\hline Male & $\frac{n}{90}$ & $\frac{\%}{60}$ & $\frac{n}{78}$ & $\frac{\%}{52}$ \\
\hline Female & 60 & 40 & 72 & 48 \\
\hline Total & 150 & 100 & 150 & 100 \\
\hline
\end{tabular}

Table: I shows among the study population diabetics male were $60 \%$, female were $40 \%$ and non-diabetics male were $52 \%$ and female were $48 \%$.

Table II: Distribution of study population according to age Age (in Diabetics ( $N=150) \quad$ Non-Diabetics $(\mathrm{N}=150)$

years)

\begin{tabular}{ccccc}
$\mathbf{3 0 - 5 0}$ & $\frac{n}{82}$ & $\frac{\%}{54.7}$ & $\frac{n}{71}$ & $\frac{\%}{47.3}$ \\
\hline $\mathbf{5 1 - 7 0}$ & 68 & 45.3 & 79 & 52.7 \\
Total & 150 & 100 & 150 & 100
\end{tabular}

Table II shows among the study population the maximum percentage of 54.7 were $30-50$ years old are diabetics.

Assessment of Dental Caries: The prevalence of Dental caries was $58.6 \%$ and $21.6 \%$ in diabetics and non diabetics. The percentage of study population with of least one missing tooth was $54.6 \%$ and $41.2 \%$ in diabetics and non diabetics. The percentage of study population with at least one restoration was more in non diabetics $32 \%$ than diabetics $16 \%$. [Figure-1]

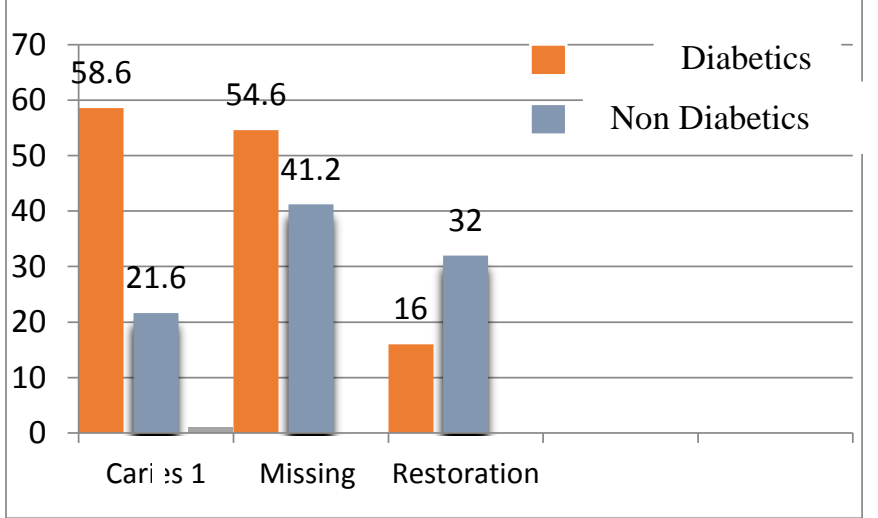

Figure-1 Prevalence of dental caries among diabetics and non-diabetics.

Assessment of Periodontal Condition (Periodontitis): The prevalence of periodontal disease (Chronic Periodontitis) was higher in diabetics (93.2\%) than non-diabetics (82.6\%). CPITN is used for the assessment. [Figure-2]

\section{Assessment of oral mucosal lesions:}

Oral mucosal lesions was assessed among diabetics and nondiabetics. Traumatic ulcer are more in diabetics (31.3\%) then non-diabetics (18\%). Non-diabetics was more in no lesion (52.7\%) then diabetics (21.4\%) [Table III]

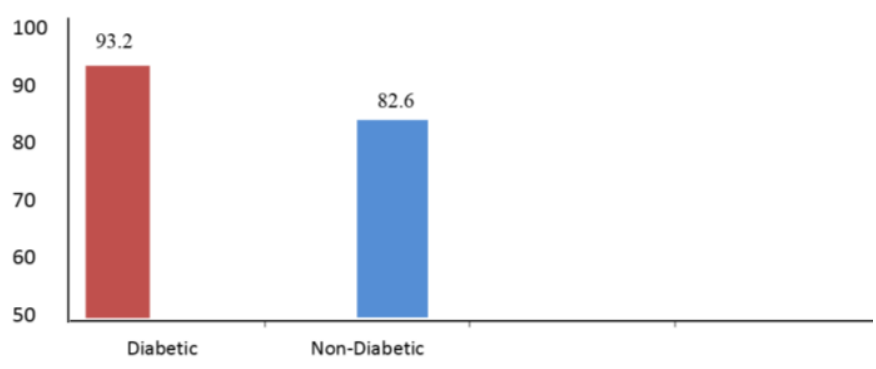

Figure-2: Prevalence of periodontal disease (Chronic Periodontitis) among diabetics and non-diabetics.

Table III: Distribution of Study population according to oral mucosal lesions:

\begin{tabular}{lllll}
\hline Oral Lesions & \multicolumn{2}{l}{ Diabetics $\mathbf{( N = 1 5 0 )}$} & $\begin{array}{l}\text { Non-Diabetics } \\
(\mathbf{N}=\mathbf{1 5 0 )}\end{array}$ \\
\hline Traumatic Ulcer & $\frac{n}{47}$ & $\frac{\%}{n 1.3}$ & $\frac{n}{27}$ & $\frac{\%}{18}$ \\
\hline Recurrent aphthous & 29 & 19.3 & 18 & 12 \\
\hline Candidiasis & 27 & 18 & 20 & 13.3 \\
\hline Lichen Plans & 15 & 10 & 6 & 4 \\
\hline No Lesion & 32 & 21.4 & 79 & 52.7 \\
\hline Total & 150 & 100 & 150 & 100
\end{tabular}

Assessment of Treatment needs:

Majority of diabetics (100\%) were required oral hygiene instruction (Treatment need 1). Professional cleaning (Treatment need 2 ) were required in $92.71 \%$ of diabetics and $86 \%$ of non-diabetics. Periodontal surgery (Treatment Need 3 ) were needed in $56.7 \%$ of diabetics $24 \%$ of non-diabetics. [Table IV]

Table IV: Distribution of study population according to treatment needs

\begin{tabular}{|c|c|c|c|c|}
\hline \multirow[t]{2}{*}{ Treatment Needs } & \multicolumn{2}{|c|}{ Diabetics ( $N=150)$} & \multicolumn{2}{|c|}{$\begin{array}{l}\text { Non-Diabetics } \\
(\mathrm{N}=150)\end{array}$} \\
\hline & $n$ & $\%$ & $n$ & $\%$ \\
\hline TN 1 & 150 & 100 & 141 & 94 \\
\hline TN 2 & 139 & 92.7 & 129 & 86 \\
\hline TN 3 & 85 & 56.7 & 36 & 24 \\
\hline
\end{tabular}

DISCUSSION: Diabetes mellitus is a metabolic diseases that causes high blood sugar. Diabetes is measured by both history taking and plasma glucose test. Mean blood glucose level in diabetic $11.2 \mathrm{mmol} / \mathrm{L}$ and in non diabetic $6.2 \mathrm{mmol} / \mathrm{L}$.

In our study prevalence of Dental Caries was more in diabetics than in non-diabetics. [Fig-1]. Similar study done by jonathan et $\mathrm{al}^{4}$ who shows that diabetics increase the dental caries because low salivary flow and increase level of blood and salivary glucose that allow dental plaque to build upon teeth that higher the risk of dental caries in diabetic patients. Other study such as Irab et $\mathrm{al}^{5}$ who also found the higher carious lesion in diabetic patient due to increase blood glucose level and intake of carbohydrate containing food.

In this study prevalence periodontal disease was more in

Website: https://www.banglajol.info/index.php/UpDCJ 
diabetics then non-diabetics [Fig-2]. Similar study was reported by JV bharatesh et al $^{6}$ who agree that diabetic patients has higher in periodontal disease than in nondiabetics due to gingival recession and alveolar bone resorption. Other researcher, such as $\mathrm{G}$. Rutger et $\mathrm{al}^{7}$ also agree with this study. Epidemiological study, WA Soskolne ${ }^{8}$ and American academy of periodontology/perio.org also found the similar result and those researcher are also agree with this above report/result. In this study, oral mucosal lesions was more in diabetics than non-diabetics because of lower resistance to infection. Similar report was found in Miguel franklin alves silva et $\mathrm{al}^{9}$ who did a study on prevalence of oral mucosal lesions in diabetic patients.

All levels of treatment needs was found to be high in diabetics than in non-diabetics in this study. These report did not agree with basic and plancak $^{10}$ who study that lower treatment needs in both the groups because in consciousness and motivate the patients toward dental treatment and patients perception of dental treatment required in different societies. CONCLUSION:

Diabetes mellitus is most common health problem in developing countries. Regular oral care in necessary for diabetic patients. This disease/condition is increasing day by day due to physical inactivity. If this condition is uncontrolled causes oral health problem as well as also developed pathologic lesion.

From this study, we are found that prevalence of dental caries and periodontal disease was high in diabetics than nondiabetics. All the treatment needs were more in diabetics than non-diabetics. Complex treatment required more in diabetics than non-diabetics. So regular dental care in necessary for diabetic patients.

CONFLICT OF INTEREST: Author declared no conflict of interest.

\section{Citation:}

Mohammad Nazmul Kabir, Md. Monoarul Islam, \& Md. Shahrin Tarafder. Diabetics and Oral Health: A Case-Control Study . Update Dental College Journal, 11(2), 32-34.

https://doi.org/10.3329/updcj.v11i2.56093

\section{REFRENCES:}

1. Sir Stanley Davidson, J. Alastair Innes, Simon Maxwell, Davidson's essential of medicine (22nd edition). page 381-92.

2. Pouya saeedi, Inga Petersohn, Paraskevi Salpea. Global and Regional Diabetes prevalence estimates for 2019 and projections for 2030 and 2015. Results from the International Diabetes Federation, Diabetes atlas, 9th Edition. November 2019; Vol 157; 107843.

https://doi.org/10.1016/j.diabres.2019.107843

PMid:31518657

34| P a g e
3. S Mahbub, S Ferdouse, MH Zaman, oral health problems of diabetic patients. Bangladesh Journal of dental Research and Education https://doi.org/10.3329/bjdre.v3i2.16610

2013;vol3;no.2

4. Jonathan ship, D.M.D. Diabetics and oral health. The journal of American Dental association. 2003 October 01; Vol 134; Page 410. https://doi.org/10.14219/iada.archive.2003.0367 PMid:18196667

5. Irab. Lamster, Evabthia Lalla, Wenches Borgnakke and George. W Taylor. The Relationship between oral health and diabetics mellitus. The Journal of American Dental Association. 2008

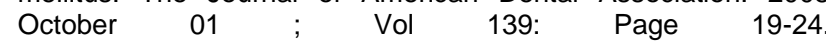
https://doi.org/10.14219/iada.archive.2008.0363 PMid:18809650

6. JV Bharatesh Monsoor Ahmed and Ganganna Kokila. Diabetics and oral health a case-control study int J Prev med. 2012 Nov; 3 (11) 806-809.

7. G Rutger person, DDS, PhD, Diabetes and periodontal disease: An update for health care providers. Diabetes spectrum. $2011 \mathrm{Nov} ; 24$ (4): https://doi.org/10.2337/diaspect.24.4.195

195-198.

8. WA soskolne. Epidemiological and clinical aspects of periodontal disease in diabetes. Ann periodontal. 1998 JUL: 3(1): 3-12

9. Miguel Franklin Alves Silva, Kevan Gullherme Nobrega Barbosa and Jozinete vietre Pereira et al. Prevalence of oral mucosal lesions among patients with diabetes mellitus type 1 and 2 . An bras Dermatol. 2015 Jan-Feb; $90(1)$ : $49-53$ https://doi.org/10.1590/abd1806-4841.20153089 PMid:25672299 PMCid:PMC4323698

10. Bacic M. Assessment of periodontal disease in diabetes patients. J Periodontal. $1989 ; \quad$ 59:816-22. https://doi.org/10.1902/jop.1988.59.12.816 PMid:3225728 